\title{
Article \\ Coexistence of Three Dominant Bacterial Symbionts in a Social Aphid and Implications for Ecological Adaptation
}

\author{
Qian Liu (D), Hui Zhang (D), Lingda Zeng, Yuhua Yu, Xiaolan Lin and Xiaolei Huang *(D) \\ State Key Laboratory of Ecological Pest Control for Fujian and Taiwan Crops, College of Plant Protection, \\ Fujian Agriculture and Forestry University, Fuzhou 350002, China; liuqian9502@163.com (Q.L.); \\ zhanghui1903@163.com (H.Z.); lingdazeng@126.com (L.Z.); yuhuaakx@foxmail.com (Y.Y.); \\ linxl@fafu.edu.cn (X.L.) \\ * Correspondence: huangxl@fafu.edu.cn; Tel.: +86-0591-83705205
}

Citation: Liu, Q.; Zhang, H.; Zeng, L.; Yu, Y.; Lin, X.; Huang, X.

Coexistence of Three Dominant Bacterial Symbionts in a Social Aphid and Implications for Ecological Adaptation. Insects 2021, 12, 416. https://doi.org/10.3390/insects 12050416

Academic Editor: Michael J. Brewer

Received: 30 March 2021

Accepted: 3 May 2021

Published: 6 May 2021

Publisher's Note: MDPI stays neutral with regard to jurisdictional claims in published maps and institutional affiliations.

Copyright: (c) 2021 by the authors. Licensee MDPI, Basel, Switzerland. This article is an open access article distributed under the terms and conditions of the Creative Commons Attribution (CC BY) license (https:// creativecommons.org/licenses/by/ $4.0 /)$.
Simple Summary: Most insects are associated with a variety of symbionts that play a crucial role in insect life history. Symbiosis of aphids and their symbionts is a good model system to study insectsymbiont interactions. Pseudoregma bambucicola is a typical social aphid that lives parthenogenetically throughout the year on bamboos in subtropical areas, and it is the only aphid that exclusively feeds on the hard stalks of bamboo. In this study, we surveyed the symbiotic bacterial community associated with P. bambucicola. Our results showed that the diversity of P. bambucicola microbiome was low, but three symbionts, namely the primary endosymbiont Buchnera and two secondary symbionts (Pectobacterium and Wolbachia), were stable coexisting with a high infection rate. Combined with the biology of P. bambucicola, we speculate that Pectobacterium may help P. bambucicola feed on the stalks of bamboo, and Wolbachia may regulate the loss of sexual reproduction or has a nutritional role in P. bambucicola. These findings will advance our knowledge of the microbiomes of social aphids and set the foundation for further studies on the functional roles of P. bambucicola symbionts.

Abstract: Aphids are associated with an array of symbionts that have diverse ecological and evolutionary effects on their hosts. To date, symbiont communities of most aphid species are still poorly characterized, especially for the social aphids. In this study, high-throughput 16S rDNA amplicon sequencing was used to assess the bacterial communities of the social aphid Pseudoregma bambucicola, and the differences in bacterial diversity with respect to ant attendance and time series were also assessed. We found that the diversity of symbionts in P. bambucicola was low and three dominant symbionts (Buchnera, Pectobacterium and Wolbachia) were stably coexisting. Pectobacterium may help P. bambucicola feed on the hard bamboo stems, and genetic distance analysis suggests that the Pectobacterium in P. bambucicola may be a new symbiont species. Wolbachia may be associated with the transition of reproduction mode or has a nutritional role in P. bambucicola. Statistical tests on the diversity of bacterial communities in P. bambucicola suggest that aphid populations attended by ants usually have a significantly higher evenness than populations without ant attendance but there was no significant difference among aphid populations from different seasons.

Keywords: Buchnera; Pectobacterium; Wolbachia; endosymbiont; social aphid; ecological function

\section{Introduction}

Associations between bacteria and insects are widespread in nature. Bacterial symbionts associated with insects may have diverse ecological and evolutionary effects on their hosts [1-4]. For examples, Wolbachia are widespread in insects as master manipulators of host biology [1], and Buchnera and Wigglesworthia provide essential nutrients to their host aphids and tsetses, respectively [5,6]. The microbiota of the insect gut often plays an important role in regulating the host's metabolism [7].

Phloem sap-feeding aphids (Hemiptera: Aphididae) feed on a wide variety of host plant species, they represent serious pests and act as vectors of phytopathogenic viruses 
and bacteria $[8,9]$. The symbiotic relationship that aphids form with many beneficial intracellular bacteria is believed to be one of the major reasons for their ecological success $[10,11]$. The symbiont communities associated with aphids are diverse and they form one of the most studied model systems for investigation of bacteria-insect symbiosis. Nearly all aphids are infected with the obligate endosymbiont Buchnera aphidicola [6], which are localized within specific cells, i.e., the bacteriocytes, and are strictly vertically transmitted from mother to offspring [6]. Aphid hosts can get essential amino acids and vitamins from Buchnera, which are scanty in the phloem sap diet [6,12].

In addition to Buchnera, aphids may harbor one or several secondary or facultative symbionts [13]. Unlike Buchnera, those diversified bacterial lineages are horizontally transferred within and across host species in addition to vertical transmission, and they usually occur in a fraction of host populations. Although facultative symbionts may be non-essential for host survival, they provide ecological benefits for hosts, such as host plant use [2], defense against pathogens and natural enemies [14,15], body color regulation [16], heat tolerance [17], and manipulation of host reproduction [18]. The positive relation between secondary endosymbionts and plant utilization of aphid hosts has been reported by some studies $[2,19,20]$. In pea aphid populations in Japan, Regiella insecticola infection may improve the fitness of the pea aphids specifically on white clover [2]. The effects on plant-specific fitness of infection of this secondary endosymbiont can also occur in pea aphid populations in Californian and France [21,22]. It has been reported that one symbiont occurs more frequently in unrelated aphid species that feed on certain plant genera, and aphid species that attack multiple plants often carry different symbiont complements [23].

Studies have shown that the prevalence of some symbionts in aphids is related to complex factors, such as the aphid species [24,25], the host plant association [2,26], climatic factors [26,27], and even ant attendance [28]. The diversity and prevalence of symbionts often vary between host species and populations [24,29,30], and it is possible that the same species may have different symbiotic communities at different times. Therefore, high-resolution time series data should provide a much more precise understanding of the aphid-symbiont relationship and help discriminate between bacteria that are prevalent with stable functioning in one species and those that only exist in some individuals. The mutualistic relationships between certain ants and aphid species are well known. Fischer et al. (2015) reported that microorganisms living in aphid honeydew may be able to alter emissions of volatile organic compounds (VOCs) and significantly mediate ant partner attraction [31], suggesting a possible relation between aphid symbiont composition and stability of aphid-ant mutualism.

Although relationships between aphids and symbiotic bacteria have received considerable attention, most previous studies have focused on the model pea aphid, Acyrthosiphon pisum [13]. The knowledge of diversity and function of symbiotic bacteria of other aphid species remains limited. Our current study focuses on a social aphid Pseudoregma bambucicola (Takahashi), which belongs to the tribe Cerataphidini and is mainly distributed in subtropical areas of Asia. This species has a complex life history and interesting biological traits [32,33]. In specific high-altitude areas of Taiwan Island, it can alternate between sexual and asexual generations on primary host plants, Styrax species, and secondary host plants, usually Bambusa bamboos, respectively. However, throughout most of its distribution, including areas such as southern China and southern Japan (the Ryukyus, Kyushu and Shikoku), P. bambucicola reproduces parthenogenetically all year around and forms dense colonies on bamboo stems [34]. Like other social insects, P. bambucicola produces soldier individuals to protect clones from natural enemies [34]. Small clones of P. bambucicola on bamboos are often attended by ants and with few soldiers, while most large colonies produce numerous soldiers and do not maintain an association with ants [35]. The attraction of ants may be an alternative way that aphids use to protect themselves from natural enemies. For P. bambucicola populations, it will be interesting to investigate whether the composition of symbiotic bacteria is influenced by ant attendance or not. Moreover, based on accumulated evidence [34] and our long-term field observations, P. bambucicola is 
probably the most specialized aphid species feeding on the hard stem of bamboo, while the other aphid species using bamboos as host plants usually feed on leaves or other softer parts [34]. We may therefore hypothesize that in P. bambucicola there should be a relation between specific symbiotic bacteria and utilization of the hard stem of bamboo. Although P. bambucicola can be a good choice to study ecological complexity and symbiotic association, most previous studies of this species have been conducted on field ecology [36] and behavior [32,35], but no study has specifically aimed to analyze the diversity of symbionts within this species.

The rapid development of high-throughput sequencing has made it easier to detect the entire bacterial communities of insects. In contrast, although the traditional PCR-based approach has been used to detect specific symbiotic bacteria within hosts, it may omit many other non-target cohabiting bacteria. In this study, the $16 \mathrm{~S}$ rRNA gene amplicon sequencing was used to assess the entire symbiotic bacterial community of the social aphid P. bambucicola. We also examined whether the symbiotic bacterial composition can be stable along a time series (in different seasons) and whether it can be influenced by ant attendance or not.

\section{Materials and Methods}

\subsection{Aphid Collection}

Aphid samples from twenty-eight P. bambucicola populations on Bambusa bamboos in subtropical areas of southern China were collected from August 2015 to January 2018. Detailed sampling information is listed in Table 1. In order to examine temporal dynamics of the symbiotic bacterial community of P. bambucicola, the samples from Fujian province were assigned into four groups based on seasons of a year ('Time groups' in Table 1). These samples were also divided into two groups based on whether the collected aphid clones were attended by ants or not ('Ant groups' in Table 1). Each sample comprised of multiple individuals collected from one same aphid colony from a single bamboo stem. The number of aphids contained in each sample ranged from a few dozen to a few hundred, depending on the size of the clone. The specimens were kept in $95 \%$ ethanol and store at $-20^{\circ} \mathrm{C}$ after collection.

\subsection{DNA Extraction}

An apterous adult aphid from each sample was washed three times in ultrapure water. Total genomic DNA was extracted from whole individuals with the DNeasy Blood \& Tissue kit (QIAGEN) according to the manufacturer's instructions. DNA extraction was carried out in an ultra-clean workbench to avoid contamination of environmental DNA. The bacterial universal primers 8F (5'-AGAGTTTGATCCTGGCTCAG-3') and 1492R (5'-GGTTACCTTGTTACGACTT-3') [37] were used to verify the success and quality of the DNA extractions. To assure the accuracy of results, sterile deionized water was used as a negative control. PCR amplifications were performed in $25 \mu \mathrm{L}$ reactions containing $1 \mu \mathrm{L}$ of DNA, $2.5 \mu \mathrm{L} 10 \times$ LA PCR buffer II $\left(\mathrm{Mg}^{2+}\right.$ plus), $0.5 \mu \mathrm{L}$ dNTP mixture $(2.5 \mathrm{mM}$ each), $0.5 \mu \mathrm{L}$ of each primer $(10 \mu \mathrm{M}), 0.5 \mu \mathrm{L}$ of TaKaRa LA Taq (5 U/ $\mu \mathrm{L})$ (TaKaRa Bio Inc., Otsu, Japan), and $19.5 \mu \mathrm{L}$ water. Amplification was performed in ProFlex ${ }^{\mathrm{TM}}$ Base (Applied Biosystems, Inc., Waltham, United States), using the following cycling conditions: $94{ }^{\circ} \mathrm{C}$ for $4 \mathrm{~min}$, followed by 30 cycles of $30 \mathrm{~s}$ at $94{ }^{\circ} \mathrm{C}, 40 \mathrm{~s}$ at $65^{\circ} \mathrm{C}, 90 \mathrm{~s}$ at $72{ }^{\circ} \mathrm{C}$, and a final extension of $10 \mathrm{~min}$ at $72{ }^{\circ} \mathrm{C}$. The PCR products were detected on $1 \%$ agarose gels, and the positive samples with a bright band of about $1500 \mathrm{bp}$ were kept at $-20^{\circ} \mathrm{C}$ until $16 \mathrm{~S}$ library preparation. The negative controls had no bands.

\section{3. $16 S$ rRNA Gene Amplification and Sequencing}

The primers 338F (5'-ACTCCTACGGGAGGCAGCA-3') and 806R (5'-GGACTACHVG GGTWTCTAAT- $3^{\prime}$ ) [38] were used to amplify the V3 and V4 regions of the $16 \mathrm{~S}$ ribosomal RNA (rRNA) gene with $95^{\circ} \mathrm{C}$ for $5 \mathrm{~min}(1 \mathrm{cycle}), 95^{\circ} \mathrm{C}$ for $30 \mathrm{~s}, 50{ }^{\circ} \mathrm{C}$ for $30 \mathrm{~s}, 72{ }^{\circ} \mathrm{C}$ for $40 \mathrm{~s}$ ( 25 cycles), followed by $72{ }^{\circ} \mathrm{C}$ for $7 \mathrm{~min}$. The PCR products were purified, quantified, and 
homogenized to form a sequencing library. The established library was checked for quality first, and paired-end sequencing of the $16 \mathrm{~S}$ rDNA was conducted on Illumina HiSeq 2500 with $2 \times 250$ bp reads (Illumina, Inc., San Diego, CA, USA) at Biomarker Bioinformatics Technology, Co., Ltd. (Beijing, China).

Table 1. Information of Pseudoregma bambucicola samples used in this study.

\begin{tabular}{ccccc}
\hline Sample ID & Collection Dates & Ant Groups & Time Groups & Collection Localities \\
\hline JZ1 & 5 January 2017 & B & 4 & Fuzhou, Fujian \\
JZ2 & 8 January 2017 & A & 4 & Fuzhou, Fujian \\
JZ3 & 18 January 2017 & B & 4 & Xiamen, Fujian \\
JZ4 & 17 February 2017 & B & 4 & Fuzhou, Fujian \\
JZ5 & 3 March 2017 & B & 1 & Fuzhou, Fujian \\
JZ6 & 14 April 2017 & A & 1 & Fuzhou, Fujian \\
JZ7 & 14 April 2017 & A & 1 & Fuzhou, Fujian \\
JZ8 & 7 May 2017 & B & 1 & Fuzhou, Fujian \\
JZ9 & 20 May 2017 & A & 1 & Fuzhou, Fujian \\
JZ10 & 9 June 2017 & A & 2 & Fuzhou, Fujian \\
JZ11 & 9 June 2017 & B & 2 & Fuzhou, Fujian \\
JZ12 & 22 June 2017 & A & 2 & Xiamen, Fujian \\
JZ13 & 22 June 2017 & B & 2 & Xiamen, Fujian \\
JZ14 & 30 June 2017 & B & 2 & Fuzhou, Fujian \\
JZ15 & 15 August 2016 & & & Linhai, Zhejiang \\
JZ16 & 22 August 2015 & & & Leshan, Sichuan \\
JZ17 & 22 September 2017 & A & 3 & Fuzhou, Fujian \\
JZ18 & 26 September 2017 & A & 3 & Fuzhou, Fujian \\
JZ19 & 20 October 2017 & A & 3 & Fuzhou, Fujian \\
JZ20 & 20 October 2017 & B & 3 & Fuzhou, Fujian \\
JZ21 & 4 November 2017 & B & 3 & Fuzhou, Fujian \\
JZ22 & 4 November 2017 & A & 3 & Fuzhou, Fujian \\
JZ23 & 10 November 2017 & A & 3 & Fuzhou, Fujian \\
JZ24 & 10 November 2017 & B & 3 & Fuzhou, Fujian \\
JZ25 & 6 December 2017 & B & 4 & Fuzhou, Fujian \\
JZ26 & 22 December 2017 & B & 4 & Fuzhou, Fujian \\
JZ27 & 17 January 2018 & B & 4 & Fuzhou, Fujian \\
JZ28 & 17 January 2018 & B & 4 & Fuzhou, Fujian \\
\hline
\end{tabular}

Note: For the 'Ant groups,' A represents aphid clones attended by ants, while B represents aphid clones not attended by ants. For the 'Time groups,' group 1 represents samples collected from the spring (March to May), while groups 2, 3, 4 represent samples from the summer (June to August), autumn (September to November) and winter (December to February), respectively.

\subsection{OTU Clustering and Taxonomic Assignment}

According to the overlap relation between paired-end reads, the PE reads were merged into single, longer raw tags using FLASH v1.2.11 [39]. Raw tags were further quality trimmed to obtain clean tags using Trimmomatic v0.33 [40] ensuring $>20$ quality scores on a sliding window of $50 \mathrm{bp}$. The chimera sequences were identified and removed using the UCHIME v8.1 [41]. Sequences with $\geq 97 \%$ similarity were assigned to the same operational taxonomic units (OTUs) using USEARCH v10.0 [42]. OTUs with a number of sequences $<0.005 \%$ of the total number of sequences were discard [43]. Representative sequences from each OTU were screened for further annotation. For each representative sequence, the Silva [44] was used with the RDP classifier v2.2 [45] to annotate taxonomic information. To further confirm the taxonomic assignment, the representative OTU sequences were compared to the sequences in GenBank using BLAST.

The results of taxonomic assignment of two dominant bacteria, Pectobacterium and Wolbachia, were further confirmed by reconstructing phylogenetic trees. The representative sequence of the most abundant OTU of Pectobacterium (OTU3) was extracted. Representative $16 \mathrm{~S}$ rDNA sequences of Pectobacterium, Dickeya, and Erwinia were downloaded from GenBank. Sequences were aligned using MAFFT v 7.427 [46] with removal of sequences not in the same regions using MEGA 7.0 [47], and Escherichia coli (GenBank accession 
number, NR_024570.1) was chosen as the outgroup. A total of 10 Pectobacterium sequences, 11 Dickeya sequences, and 4 Erwinia sequences of 434 bp length were used to construct a maximum likelihood (ML) phylogenetic tree. In addition, the representative OTU sequence of Wolbachia (OTU5) was also extracted, and representative 16S sequences of Wolbachia were downloaded from GenBank. All sequences of Wolbachia were treated with the same steps as Pectobacterium, and Rickettsia endosymbiont (GenBank accession number, LN829697.2) was chosen as the outgroup. Finally, 29 Wolbachia sequences of $409 \mathrm{bp}$ length were used to construct a ML phylogenetic tree. The phylogenetic trees of Pectobacterium and Wolbachia were reconducted by IQ-TREE v1.6.8 using the HKY+F+R2 model with 2000 SH-aLRT bootstrap replicates [48]. The pairwise genetic distances among those two sequence datasets were also calculated in MEGA 7.0 with the Kimura 2-parameter (K2P) model [49].

\subsection{Microbiome Diversity}

Species richness (Chao1 and ACE), diversity (Simpson and Shannon), and the coverage of library for each aphid sample were calculated in Mothur v.1.30 [50]. The Chao1 and ACE indices indicate species richness (number of microbial species). The Shannon and Simpson indices measure species diversity by taking into consideration species abundance and species evenness in the sample community. In the case of same species richness, the larger Shannon index and smaller Simpson index indicate the larger evenness of each species and the greater diversity of community [51]. These different indices for the 'Ant groups' and 'Time groups' were then compared, respectively, using one-way ANOVA with the IBM Statistical Package for the Social Sciences (SPSS) version 24.0 (Chicago, IL, USA).

\section{Results}

\subsection{Library Basic Statistics}

Using Illumina's stringent quality control (QC), we obtained a total of 2,150,533 Clean tags. The mean number of Clean tags generated for each sample was 76,805 $(\mathrm{SD}=19,897.854)$. After sequence filtering steps, we obtained 2,093,909 reads (Table S1). The assembly of paired sequences resulted in consensus sequences with an average length of $431 \mathrm{bp}$.

\subsection{OTU Clustering and Taxonomic Assignment}

High-quality reads were clustered using > 97\% sequence similarity into 23 microbial OTUs (Table 2); the number of OTU in each sample is presented in Table S2. Table S3 shows the details of OTUs distribution in all samples, the raw sequences have been submitted to the NCBI Sequence Read Archive (accession number: PRJNA634633).

Of the total reads for 28 P. bambucicola samples, 99.94\% OTUs were classified as Proteobacteria and most bacteria were from the Enterobacteriaceae $(98.45 \%$ of the total reads). The obligate endosymbiont Buchnera was the most abundant taxon and was detected in all aphid samples (89.07\% of the total reads) and was represented by two OTUs (OTU1, 56). Other taxa with relatively high abundance included Pectobacterium $(6.56 \%$, OTU3, 9 , 104, 322, 427), Wolbachia (0.97\%, OTU5), Serratia (1.72\%, OTU2), and Arsenophonus (1.09\%, OTU4). It is worth noting that Pectobacterium was detected in 26 of 28 aphid samples, and its relative abundance fluctuated between $0.73 \%$ and $14.41 \%$ in different samples. A similar situation occurred for Wolbachia which was detected in 23 of 28 aphid samples, with relative abundance fluctuating between $0.14 \%$ and $6.33 \%$. Whilst another well-known insect symbiont, Serratia, was detected in 13 samples, its relative abundance was $\leq 0.01 \%$ (reads number <5) in 11 of the 13 samples. Arsenophonus sequences were represented in six aphid samples, but four of which had a relative abundance $\leq 0.01 \%$ (reads number $<12$ ). Table 3 shows the detailed information of the top five most abundant bacteria. The relative abundance of the top five genera in 28 samples are illustrated in Figure 1a, while the relative abundance of three dominant symbionts in all samples are shown in Figure $1 \mathrm{~b}$. 
Table 2. Taxonomic assignment of bacterial OTUs in Pseudoregma bambucicola.

\begin{tabular}{cc}
\hline OTU ID & Taxon Annotation \\
\hline OTU1 & Buchnera \\
OTU56 & Buchnera \\
OTU3 & Pectobacterium \\
OTU104 & Pectobacterium \\
OTU322 & Pectobacterium \\
OTU427 & Pectobacterium \\
OTU9 & Pectobacterium \\
OTU5 & Wolbachia \\
OTU6 & Orbaceae sp. \\
OTU2 & Serratia \\
OTU4 & Arsenophonus \\
OTU7 & Nocardioides \\
OTU8 & Candidatus_Alysiosphaera \\
OTU10 & Acinetobacter \\
OTU11 & Escherichia-Shigella \\
OTU12 & Thiothrix \\
OTU13 & Sphaerotilus \\
OTU14 & Nicotiana \\
OTU15 & OTU16 \\
OTU17 & OTU19 \\
OTU24 & Microbacterium \\
\hline
\end{tabular}

Table 3. Reads and relative abundance of symbiotic bacteria in each sample, emphasizing the major five bacteria.

\begin{tabular}{|c|c|c|c|c|c|c|}
\hline Sample ID & Buchnera & Pectobacterium & Wolbachia & Serratia & Arsenophonus & Other \\
\hline $\mathrm{JZ1}$ & $41,346(95.96 \%)$ & $1633(3.79 \%)$ & $59(0.14 \%)$ & 0 & 0 & $47(0.11 \%)$ \\
\hline $\mathrm{JZ2}$ & $25,062(53.07 \%)$ & $1139(2.41 \%)$ & $541(1.15 \%)$ & $20,472(43.35 \%)$ & 0 & $8(0.02 \%)$ \\
\hline $\mathrm{JZ3}$ & $34,163(98.16 \%)$ & $253(0.73 \%)$ & $138(0.40 \%)$ & $2(0.01 \%)$ & 0 & $249(0.72 \%)$ \\
\hline $\mathrm{JZ4}$ & $67,789(92.58 \%)$ & $4963(6.78 \%)$ & $376(0.51 \%)$ & $4(0.01 \%)$ & 0 & $88(0.12 \%)$ \\
\hline JZ5 & $46,056(92.75 \%)$ & 3568 (7.19\%) & 0 & 0 & 0 & $30(0.06 \%)$ \\
\hline JZ6 & $57,971(87.84 \%)$ & $6923(10.49 \%)$ & $1075(1.63 \%)$ & 3 & 0 & $22(0.03 \%)$ \\
\hline $\mathrm{JZ7}$ & $50,186(82.96 \%)$ & $6450(10.66 \%)$ & $3830(6.33 \%)$ & 0 & 0 & $26(0.04 \%)$ \\
\hline JZ8 & $57,740(87.75 \%)$ & $7604(11.56 \%)$ & $405(0.62 \%)$ & 1 & 0 & $50(0.08 \%)$ \\
\hline JZ9 & $38,469(66.20 \%)$ & $3637(6.26 \%)$ & $412(0.71 \%)$ & $15,569(26.79 \%)$ & 0 & $26(0.04 \%)$ \\
\hline JZ10 & $94,714(89.45 \%)$ & $9798(9.25 \%)$ & $1345(1.27 \%)$ & 1 & 0 & $22(0.02 \%)$ \\
\hline JZ11 & $82,091(93.06 \%)$ & $5344(6.06 \%)$ & 768 (0.87\%) & 1 & 0 & $11(0.01 \%)$ \\
\hline $\mathrm{JZ12}$ & $90,991(88.99 \%)$ & $10,331(10.10 \%)$ & $857(0.84 \%)$ & 0 & 0 & $74(0.07 \%)$ \\
\hline JZ13 & $53,563(88.38 \%)$ & $6353(10.48 \%)$ & $635(1.05 \%)$ & 1 & 0 & $51(0.08 \%)$ \\
\hline JZ14 & $66,412(92.21 \%)$ & $5434(7.54 \%)$ & 0 & 1 & 1 & $178(0.25 \%)$ \\
\hline JZ15 & $67,531(81.39 \%)$ & 0 & $639(0.77 \%)$ & 1 & $14,721(17.74 \%)$ & $76(0.09 \%)$ \\
\hline JZ16 & $66,655(90.39 \%)$ & $3465(4.70 \%)$ & 0 & 0 & 0 & $3618(4.91 \%)$ \\
\hline JZ17 & $76,662(89.77 \%)$ & $8129(9.52 \%)$ & $493(0.58 \%)$ & 0 & 2 & $111(0.13 \%)$ \\
\hline JZ18 & $60,662(85.53 \%)$ & $10,221(14.41 \%)$ & 0 & 0 & 0 & $44(0.06 \%)$ \\
\hline JZ19 & 73,599 (93.77\%) & $4408(5.62 \%)$ & $440(0.56 \%)$ & 0 & 0 & $45(0.06 \%)$ \\
\hline JZ20 & $81,166(94.56 \%)$ & $4039(4.71 \%)$ & $592(0.69 \%)$ & 0 & 0 & $42(0.05 \%)$ \\
\hline JZ21 & $99,098(90.82 \%)$ & $8526(7.81 \%)$ & $1457(1.34 \%)$ & 0 & 1 & $37(0.03 \%)$ \\
\hline JZ22 & $81,033(92.90 \%)$ & $5319(6.10 \%)$ & $828(0.95 \%)$ & 0 & $11(0.01 \%)$ & $36(0.04 \%)$ \\
\hline JZ23 & $66,941(81.64 \%)$ & 1 & 0 & 0 & $8133(9.92 \%)$ & $6924(8.44 \%)$ \\
\hline JZ24 & $87,857(88.92 \%)$ & $8940(9.05 \%)$ & $1880(1.90 \%)$ & 1 & 0 & $131(0.13 \%)$ \\
\hline JZ25 & $\begin{array}{c}101,550 \\
(96.83 \%)\end{array}$ & $1745(1.66 \%)$ & $1406(1.34 \%)$ & 0 & 0 & $169(0.16 \%)$ \\
\hline JZ26 & $61,911(97.40 \%)$ & $1498(2.36 \%)$ & $115(0.18 \%)$ & 0 & 0 & $39(0.06 \%)$ \\
\hline JZ27 & $88,619(96.90 \%)$ & $2230(2.44 \%)$ & 535 (0.59\%) & 1 & 0 & $65(0.07 \%)$ \\
\hline JZ28 & $45,161(86.60 \%)$ & $5368(10.29 \%)$ & $1577(3.02 \%)$ & 0 & 0 & $43(0.08 \%)$ \\
\hline
\end{tabular}



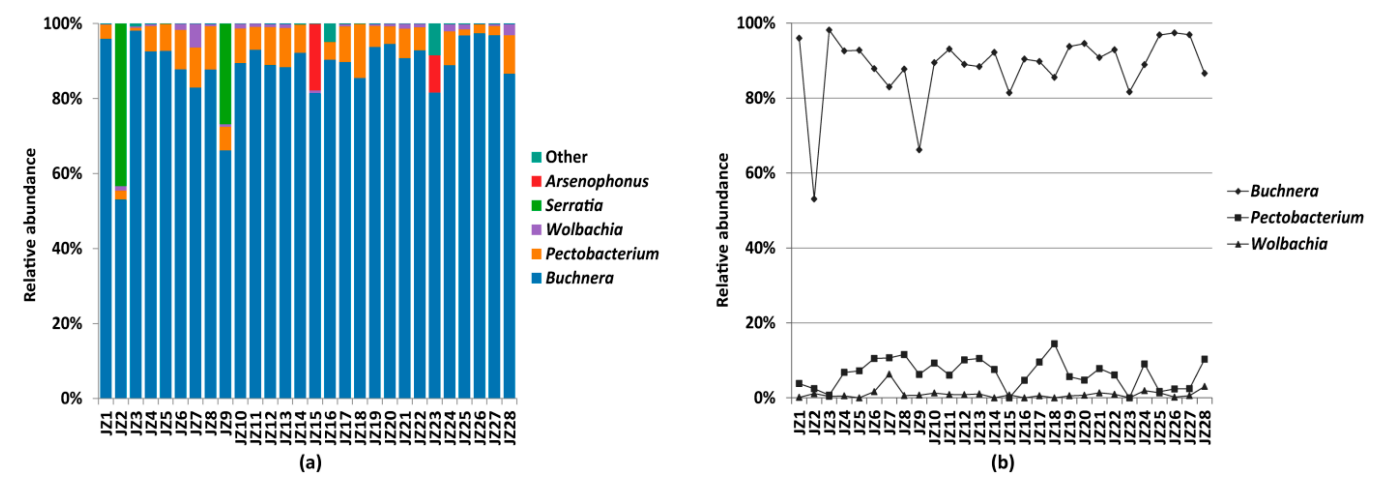

Figure 1. (a) Taxonomic composition and relative abundance of symbiotic bacteria at genus level for all Pseudoregma bambucicola samples; (b) relative abundance of the three dominant symbionts.

In the Pectobacterium phylogenetic tree (Figure 2a), OTU3 and other Pectobacterium species clustered together, while Dickeya and Erwinia formed separate clades, respectively. The genetic distances between OTU3 and all other Pectobacterium sequences ranged from $2.1 \%$ to $3.9 \%$, which indicated that the Pectobacterium symbiont in P. bambucicola may represent a new bacterial species of this genus. As the Wolbachia phylogenetic tree (Figure 2b) shows, with a low support OTU5 and several other Wolbachia strains from aphids clustered together, and Wolbachia strains of other arthropods and nematodes separated from this clade. The genetic distances between OTU5 and all other Wolbachia sequences ranged from 0 to $3.8 \%$, while the V3-V4 region of 16s rDNA sequence of Wolbachia from P. bambucicola was identical with three Wolbachia sequences from other aphids, indicating that the Wolbachia strain in P. bambucicola is a common one among aphid species.

\subsection{Microbiome Diversity for the Ant and Time Groups}

The coverage of library for each aphid sample was good, being more than 0.99 for all samples. We calculated the richness (Chao1 and ACE) and diversity (Simpson and Shannon) indices, which are shown in the Table S2. The mean Shannon diversity index was low, suggesting a low bacterial diversity in P. bambucicola and that each sample was dominated by only a few bacteria. The ant-attended aphid group had a significantly higher Shannon index $\left(F_{0.05}(1,24)=12.233, p=0.002\right)$ and lower Simpson index $\left(F_{0.05}(1,24)=11.525, p=0.002\right)$ than the aphid group not attended by ants, however, the Chao1 $\left(F_{0.05}(1,24)=0.079, p=0.781\right)$ and $\operatorname{ACE}\left(F_{0.05}(1,24)=0.002, p=0.967\right)$ indices had no significant difference (Table 4). For the four time series groups, except the ACE index, there were no significant differences for the Chao1 $\left(F_{0.05}(3,22)=1.490, p=0.245\right)$, Shannon $\left(F_{0.05}(3,22)=1.960, p=0.150\right)$, and Simpson $\left(F_{0.05}(3,22)=1.167, p=0.345\right)$ indices $($ Table 5$)$.

Table 4. Results of one-way ANOVA for the effect of ant attendance on bacterial community diversity of Pseudoregma bambucicola.

\begin{tabular}{|c|c|c|c|c|c|}
\hline Indices & Ant Groups & $n$ & $\mathbf{M} \pm \mathbf{S E}$ & $F$ & $p$-Value \\
\hline \multirow{2}{*}{$\mathrm{ACE}$} & A & 11 & $17.20 \pm 0.67$ & \multirow{2}{*}{0.002} & \multirow{2}{*}{0.967} \\
\hline & B & 15 & $17.24 \pm 0.72$ & & \\
\hline \multirow{2}{*}{ Chao1 } & A & 11 & $16.09 \pm 0.60$ & \multirow{2}{*}{0.079} & \multirow{2}{*}{0.781} \\
\hline & B & 15 & $16.32 \pm 0.55$ & & \\
\hline \multirow{2}{*}{ Simpson } & A & 11 & $0.73 \pm 0.04$ & \multirow{2}{*}{11.525} & \multirow{2}{*}{0.002} \\
\hline & B & 15 & $0.87 \pm 0.02$ & & \\
\hline \multirow{2}{*}{ Shannon } & A & 11 & $0.57 \pm 0.06$ & \multirow{2}{*}{12.233} & \multirow{2}{*}{0.002} \\
\hline & B & 15 & $0.34 \pm 0.04$ & & \\
\hline
\end{tabular}

Note: Group A and Group B represent aphid clones attended by ants or not, respectively. Significant $p$ values $(p<0.05)$ are in italics. 


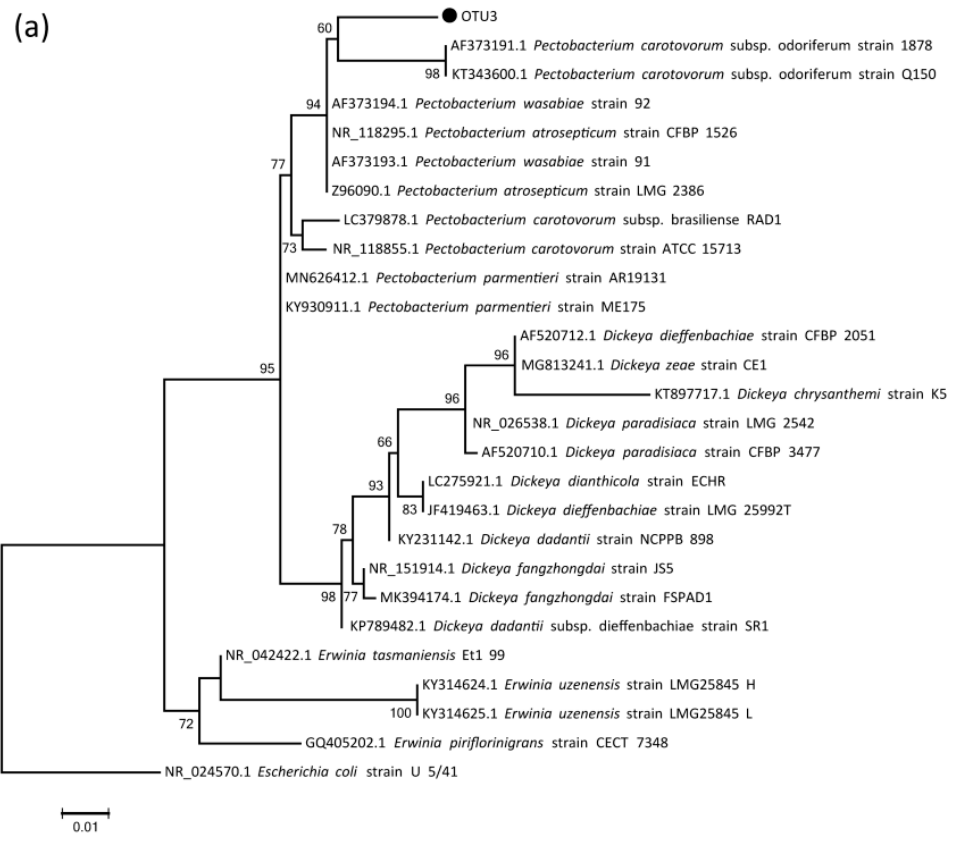

(b)

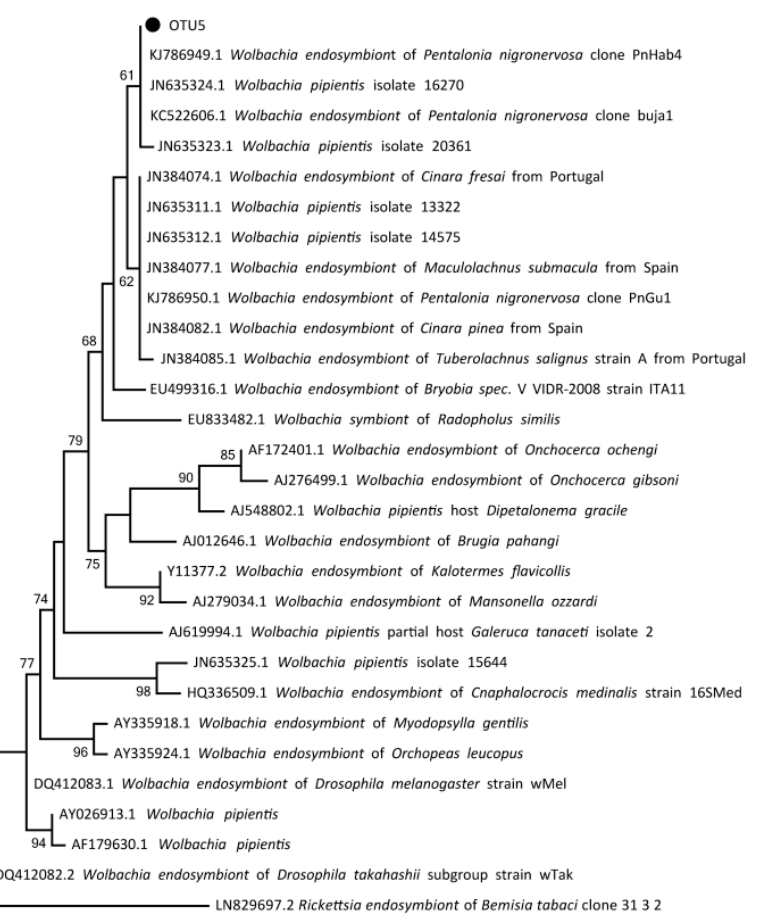

Figure 2. The maximum likelihood phylogenic tree of (a) Pectobacterium and (b) Wolbachia based on 16s rDNA V3-V4 region. OTU3 and OTU5 represent the main OTU of Pectobacterium and Wolbachia from all Pseudoregma bambucicola samples, respectively. Numbers above the branches indicate the bootstrap support values, for which lower than 50 are not shown. 
Table 5. Results of one-way ANOVA for the effect of different seasons on bacterial community diversity of Pseudoregma bambucicola.

\begin{tabular}{|c|c|c|c|c|c|}
\hline Indices & $\begin{array}{c}\text { Time } \\
\text { Groups }\end{array}$ & $n$ & $\mathbf{M} \pm \mathbf{S E}$ & $F$ & $p$-Value \\
\hline \multirow{4}{*}{$\mathrm{ACE}$} & 1 & 5 & $15.39 \pm 0.93$ & \multirow{4}{*}{3.205} & \multirow{4}{*}{0.043} \\
\hline & 2 & 5 & $19.68 \pm 1.37$ & & \\
\hline & 3 & 8 & $16.87 \pm 0.76$ & & \\
\hline & 4 & 8 & $17.18 \pm 0.64$ & & \\
\hline \multirow{4}{*}{ Chao1 } & 1 & 5 & $14.87 \pm 0.85$ & \multirow{4}{*}{1.490} & \multirow{4}{*}{0.245} \\
\hline & 2 & 5 & $17.50 \pm 1.14$ & & \\
\hline & 3 & 8 & $16.31 \pm 0.71$ & & \\
\hline & 4 & 8 & $16.19 \pm 0.55$ & & \\
\hline \multirow{4}{*}{ Simpson } & 1 & 5 & $0.73 \pm 0.06$ & \multirow{4}{*}{1.167} & \multirow{4}{*}{0.345} \\
\hline & 2 & 5 & $0.82 \pm 0.02$ & & \\
\hline & 3 & 8 & $0.81 \pm 0.03$ & & \\
\hline & 4 & 8 & $0.85 \pm 0.06$ & & \\
\hline \multirow{4}{*}{ Shannon } & 1 & 5 & $0.59 \pm 0.09$ & \multirow{4}{*}{1.960} & \multirow{4}{*}{0.150} \\
\hline & 2 & 5 & $0.43 \pm 0.03$ & & \\
\hline & 3 & 8 & $0.44 \pm 0.04$ & & \\
\hline & 4 & 8 & $0.34 \pm 0.09$ & & \\
\hline
\end{tabular}

Note: Group 1 represent samples collected from the spring (March to May), while Groups 2, 3, 4 represent samples from the summer (June to August), autumn (September to November) and winter (December to February), respectively. Significant $p$ values $(p<0.05)$ are in italics.

\section{Discussion}

Our study examined the symbiotic bacterial community harbored by the social aphid P. bambucicola and compared the microbiomes in different aphid clones of four time groups and two ant groups. Overall, $16 \mathrm{~S}$ rDNA sequencing showed a stable coexistence of three dominant bacterial symbionts, namely the primary aphid endosymbiont Buchnera, the Pectobacterium, and the Wolbachia. In addition to these three symbionts, Arsenophonus, Serratia, and Orbaceae sp., previously reported to be associated with insects, were also found with relative high abundance in our study but were only limited to a few samples (Table S3). It is notable that Arsenophonus was only infected with two samples in which Pectobacterium was absent (Table 3). The genus Arsenophonus, a group of symbionts that kill male eggs of the wasp Nasonia vitripennis [52], has also been reported in other insects [53,54], but its function in many insects is far from clear.

The clones of $P$. bambucicola were stably infected by three symbiotic bacteria genera (Buchnera, Pectobacterium, and Wolbachia). Buchnera, the obligate endosymbiont of aphids, was the most abundant symbiotic bacteria of $P$. bambucicola and was detected in all samples. Fukatsu et al. (1994), using histochemical-based approaching analyses, revealed that $P$. bambucicola contain the typical intracellular symbiont Buchnera, rather than being replaced by a yeast-like fungus [55]. The stable coexistence of two secondary endosymbiotic bacteria is not common in aphids. For example, in spite of the most studied pea aphid containing eight to nine secondary endosymbionts, double infections with two secondary symbionts were rarely detected [56,57]. Gómez-Valero et al. (2004) found a coexistence of Wolbachia and a secondary symbiont (R type, Serratia) in the aphid Cinara cedri [58]. Interestingly, the coexistence of Pectobacterium and Wolbachia with high infection rate $(78.57 \%)$ was detected in P. bambucicola. Meanwhile, compared to other aphid species with a variety of host plants, such as the pea aphid [13], the diversity of the bacterial community in P. bambucicola was low, likely because the habit (feeding on bamboo stems) of P. bambucicola is relatively simple.

High infection rates (26/28) of Pectobacterium have been detected in P. bambucicola. Such high prevalence suggests a potential functional role of Pectobacterium in this social aphid. The genus Pectobacterium are important causative agents of the soft rot disease with broad host plant ranges $[59,60]$. These bacteria produce a large amount of plant cell 
wall-degrading enzymes (PCWDEs) such as pectinases, cellulases, hemicellulases, and proteinases which makes plant tissue decay efficiently [61]. Among the over 5000 known aphid species, P. bambucicola is the only one that exclusively feeds on the hard stalks of bamboo, which consist of much harder cell walls than many other plants. To feed on the phloem sap of bamboo, aphid stylet must conquer the hindrance of the hard cell wall [62]. We speculate that Pectobacterium symbionts should help the host aphid to secrete PCWDEs, especially pectinases, to lyse and pierce the cell walls of bamboo. This may be one of the main reasons why P. bambucicola can adapt to the hard stalks of bamboo. In addition, our ongoing subsequent experiments of bacterial screening in different tissues of P. bambucicola found that Pectobacterium was mainly distributed in the ovary (unpublished data), indicating that Pectobacterium is likely a symbiotic bacterium and can vertically transmit in this aphid. It will be valuable to investigate how this symbiosis contributes to feeding adaptation of the host aphid at genomic levels for both Pectobacterium and P. bambucicola. Notably, genetic distances indicated that the Pectobacterium in P. bambucicola may be a new symbiont species and phylogenetic analysis showed that Pectobacterium as a symbiont in P. bambucicola may reflect an evolutionary transition from plant pathogen to insect symbiotic bacteria. Future localization observation such as FISH (fluorescence in situ hybridization) and comparative genomic study will also help to understand their symbiotic relationship.

Wolbachia is a widely distributed intracellular symbiont in arthropods and nematodes and is known as a reproductive manipulator [1]. It can alter the reproductive pattern of hosts in diverse ways, such as feminization, parthenogenesis, male killing, and spermegg incompatibility [1]. Wolbachia-induced female parthenogenesis has been documented in species such as mites, hymenopterans, and thrips [63-65]. In terms of aphids, a few previous PCR-based detections suggested Wolbachia does not have a high infection rate in aphids [66,67]. However, our current study indicates a high infection rate $(23 / 28)$ of Wolbachia in the social aphid P. bambucicola. Although Wolbachia-induced reproductive manipulation has been demonstrated in many arthropods, this function has not been detected in aphid species. P. bambucicola typically live in subtropical areas and reproduce parthenogenetically, but rare records of sexual generation were reported in high altitude areas of Taiwan Island [34]. Therefore, it may be possible that this aphid has been experiencing the loss of the sexual generation in its distribution areas, and the highly infected Wolbachia may potentially have a role in regulating the loss of sexual reproduction in P. bambucicola populations. On the other hand, Wolbachia was demonstrated to act as a nutritional mutualistic bacterium in other insects, such as the aphid Pentalonia nigronervosa [68] and the bedbug Cimex lectularius [3]. Whether Wolbachia has a nutritional role in P. bambucicola needs to be investigated by further studies based on genome analysis, microscopic observation, and functional verification experiments.

Aphid groups visited by ants had a significantly higher diversity of bacterial communities than those not attended by ants. However, Chao1 and ACE indices, having no significant difference, suggested that ant attendance had no influence on the richness, while the symbiotic microorganisms of aphids attended by ants had higher community evenness. Ant-attended P. bambucicola populations having higher diversity of bacterial community may indicate that ant attendance could be a selection agent for shaping different symbiotic communities, which may influence the composition of aphid honeydew and thus adjust its attraction to ant partners. Besides, it has been demonstrated in some studies that ants can protect aphid clones from parasitoids and pathogens [69,70]. Henry et al. (2015) found that Hamiltonella defensa and R. insecticola, two protective aphid symbionts, were more likely to occur in aphid species not attended by ants [23]. Mandrioli et al. (2016) found that if aphid populations recurrently tended by ants were maintained in insectaries without ants, aphids increased the amount of $H$. defensa, making the composition of their microbiome context-dependent [28]. The associations with ants or protective symbionts may be two alternative ways that aphids can protect themselves from pathogens and nature enemies. In the field, P. bambucicola often encounter many kinds of natural enemies, and ants and 
soldier aphids alternately protect the clones from natural enemies [35]. This may be the potential reason why the number of microbial species in the P. bambucicola is not affected by ant attendance. In terms of the time series groups, there was no significant difference in the composition of bacterial communities, which confirms that the microbiota is dominated by three symbionts (Buchnera, Pectobacterium, Wolbachia) and time is not an important structuring factor for bacterial communities associated with P. bambucicola.

\section{Conclusions}

In this study, we reported the symbiotic bacterial community of the social aphid $P$. bambucicola. The diversity of the bacterial community in P. bambucicola was low and the microbiota of $P$. bambucicola was dominated by three symbiotic bacteria. In addition to the obligate endosymbiont Buchnera, high infection rates of Pectobacterium $(92.9 \%)$ and Wolbachia $(82.1 \%)$ in P. bambucicola may suggest a potential functional role in P. bambucicola. Combined with the biology of $P$. bambucicola, the symbiotic Pectobacterium may help $P$. bambucicola adapt its unique niche of bamboo stems, and the well-known reproductive manipulator Wolbachia may regulate the loss of sexual reproduction or have a nutritional role in P. bambucicola. The genetic distance analysis indicated that the Pectobacterium of P. bambucicola may be a new symbiont species which needs to be further validated with more data in future studies. Moreover, our study indicates that time is not an important structuring factor for bacterial communities associated with P. bambucicola, but the evenness of microbiota in P. bambucicola attended by ants is higher than that without ant attendance.

Supplementary Materials: The following are available online at https:/ / www.mdpi.com/article/10 .3390/insects12050416/s1, Table S1: The Illumina HiSeq results of bacterial 16S rRNA genes, Table S2: Detail information of microbiome diversity indices of 28 Pseudoregma bambucicola samples, Table S3: The details of OTUs distribution in all samples.

Author Contributions: Conceptualization, X.H. and Q.L.; methodology, Q.L., H.Z. and Y.Y.; investigation, L.Z., Q.L.; resources, X.L., X.H.; data curation, formal analysis and visualization, Q.L., H.Z., Y.Y.; writing—original draft preparation, Q.L., H.Z.; writing-review and editing, X.H.; project administration and funding acquisition, X.H. All authors have read and agreed to the published version of the manuscript.

Funding: This research was funded by National Natural Science Foundation of China (Grant number: 31970446) and National Key R\&D Program of China (Grant number: 2016YFE0203100).

Data Availability Statement: The raw sequencing data are deposited in the NCBI Sequence Read Archive (SRA) database with accession number PRJNA634633.

Conflicts of Interest: The authors declare no conflict of interest.

\section{References}

1. Werren, J.H.; Baldo, L.; Clark, M.E. Wolbachia: Master manipulators of invertebrate biology. Nat. Rev. Genet. 2008, 6, 741-751. [CrossRef] [PubMed]

2. Tsuchida, T.; Koga, R.; Fukatsu, T. Host Plant Specialization Governed by Facultative Symbiont. Science 2004, 303, 1989. [CrossRef] [PubMed]

3. Hosokawa, T.; Koga, R.; Kikuchi, Y.; Meng, X.-Y.; Fukatsu, T. Wolbachia as a bacteriocyte-associated nutritional mutualist. Proc. Natl. Acad. Sci. USA 2009, 107, 769-774. [CrossRef] [PubMed]

4. Waleed, A.N.; Junaid, A.S.; Ye, L.; Huang, X. Functional interactions among phytophagous insects, plants and microbial symbionts. Wuyi Sci. J. 2020, 36, 1-15. [CrossRef]

5. Akman, L.; Yamashita, A.; Watanabe, H.; Oshima, K.; Shiba, T.; Hattori, M.; Aksoy, S. Genome sequence of the endocellular obligate symbiont of tsetse flies, Wigglesworthia glossinidia. Nat. Genet. 2002, 32, 402-407. [CrossRef] [PubMed]

6. Douglas, A.E. Nutritional Interactions in Insect-Microbial Symbioses: Aphids and Their Symbiotic Bacteria Buchnera. Annu. Rev. Èntomol. 1998, 43, 17-37. [CrossRef]

7. Engel, P.; Moran, N.A. The gut microbiota of insects-diversity in structure and function. FEMS Microbiol. Rev. 2013, 37, 699-735. [CrossRef]

8. Dedryver, C.-A.; Le Ralec, A.; Fabre, F. The conflicting relationships between aphids and men: A review of aphid damage and control strategies. Comptes Rendus Biol. 2010, 333, 539-553. [CrossRef]

9. Ng, J.C.K.; Perry, K.L. Transmission of plant viruses by aphid vectors. Mol. Plant Pathol. 2004, 5, 505-511. [CrossRef] 
10. Oliver, K.M.; Degnan, P.H.; Burke, G.R.; Moran, N.A. Facultative Symbionts in Aphids and the Horizontal Transfer of Ecologically Important Traits. Annu. Rev. Èntomol. 2010, 55, 247-266. [CrossRef]

11. Ferrari, J.; Vavre, F. Bacterial symbionts in insects or the story of communities affecting communities. Philos. Trans. R. Soc. B 2011, 366, 1389-1400. [CrossRef] [PubMed]

12. Nakabachi, A.; Ishikawa, H. Provision of riboflavin to the host aphid, Acyrthosiphon pisum, by endosymbiotic bacteria, Buchnera. J. Insect Physiol. 1999, 45, 1-6. [CrossRef]

13. Zeng, L.; Liu, Q.; Huang, X. Diversity and functions of the secondary endosymbionts in aphids. Wuyi Sci. J. 2019, 35, 4-11. [CrossRef]

14. Oliver, K.M.; Russell, J.A.; Moran, N.A.; Hunter, M.S. Facultative bacterial symbionts in aphids confer resistance to parasitic wasps. Proc. Natl. Acad. Sci. USA 2003, 100, 1803-1807. [CrossRef]

15. Łukasik, P.; van Asch, M.; Guo, H.; Ferrari, J.; Godfray, H.C.J. Unrelated facultative endosymbionts protect aphids against a fungal pathogen. Ecol. Lett. 2012, 16, 214-218. [CrossRef] [PubMed]

16. Tsuchida, T.; Koga, R.; Horikawa, M.; Tsunoda, T.; Maoka, T.; Matsumoto, S.; Simon, J.C.; Fukatsu, T. Symbiotic Bacterium Modifies Aphid Body Color. Science 2010, 330, 1102-1104. [CrossRef]

17. Burke, G.; Fiehn, O.; Moran, N. Effects of facultative symbionts and heat stress on the metabolome of pea aphids. ISME J. 2009, 4, 242-252. [CrossRef]

18. Simon, J.C.; Boutin, S.; Tsuchida, T.; Koga, R.; Le Gallic, J.-F.; Frantz, A.; Outreman, Y.; Fukatsu, T. Facultative Symbiont Infections Affect Aphid Reproduction. PLoS ONE 2011, 6, e21831. [CrossRef]

19. Ferrari, J.; Darby, A.C.; Daniell, T.J.; Godfray, H.C.J.; Douglas, A.E. Linking the bacterial community in pea aphids with host-plant use and natural enemy resistance. Ecol. Ėntomol. 2004, 29, 60-65. [CrossRef]

20. Tsuchida, T.; Koga, R.; Matsumoto, S.; Fukatsu, T. Interspecific symbiont transfection confers a novel ecological trait to the recipient insect. Biol. Lett. 2010, 7, 245-248. [CrossRef]

21. Leonardo, T.E.; Muiru, G.T. Facultative symbionts are associated with host plant specialization in pea aphid populations. Proc. R. Soc. Lond. Ser. B 2003, 270, S209-S212. [CrossRef] [PubMed]

22. Simon, J.C.; Carré, S.; Boutin, M.; Prunier-Leterme, N.; Sabater-Muñoz, B.; Latorre, A.; Bournoville, R. Host-based divergence in populations of the pea aphid: Insights from nuclear markers and the prevalence of facultative symbionts. Proc. R. Soc. Lond. Ser. B. 2003, 270, 1703-1712. [CrossRef]

23. Henry, L.M.; Maiden, M.C.J.; Ferrari, J.; Godfray, H.C.J. Insect life history and the evolution of bacterial mutualism. Ecol. Lett. 2015, 18, 516-525. [CrossRef]

24. Jones, R.T.; Bressan, A.; Greenwell, A.M.; Fierer, N. Bacterial Communities of Two Parthenogenetic Aphid Species Cocolonizing Two Host Plants across the Hawaiian Islands. Appl. Environ. Microbiol. 2011, 77, 8345-8349. [CrossRef]

25. Sepúlveda, D.A.; Zepeda-Paulo, F.; Ramírez, C.C.; Lavandero, B.; Figueroa, C.C. Diversity, frequency, and geographic distribution of facultative bacterial endosymbionts in introduced aphid pests. Insect Sci. 2017, 24, 511-521. [CrossRef] [PubMed]

26. Henry, L.M.; Peccoud, J.; Simon, J.-C.; Hadfield, J.D.; Maiden, M.J.C.; Ferrari, J.; Godfray, H.C.J. Horizontally Transmitted Symbionts and Host Colonization of Ecological Niches. Curr. Biol. 2013, 23, 1713-1717. [CrossRef] [PubMed]

27. Chen, D.Q.; Montllor, C.B.; Purcell, A.H. Fitness effects of two facultative endosymbiotic bacteria on the pea aphid, Acyrthosiphon pisum, and the blue alfalfa aphid, A. kondoi. Èntomol. Exp. Appl. 2000, 95, 315-323. [CrossRef]

28. Mandrioli, M.; Bisanti, M.; Grasso, D.A.; Manicardi, G.C. Role of ant-tending in modulating the presence of symbiotic bacteria against parasitoids in aphids. Trends Entomol. 2016, 12, 63-71.

29. Bansal, R.; Mian, M.A.R.; Michel, A.P. Microbiome diversity of Aphis glycines with extensive superinfection in native and invasive populations. Environ. Microbiol. Rep. 2013, 6, 57-69. [CrossRef]

30. Fakhour, S.; Ambroise, J.; Renoz, F.; Foray, V.; Gala, J.L.; Hance, T. A large-scale field study of bacterial communities in cereal aphid populations across Morocco. FEMS Microbiol. Ecol. 2018, 94, fiy003. [CrossRef]

31. Fischer, C.Y.; Lognay, G.C.; Detrain, C.; Heil, M.; Grigorescu, A.; Sabri, A.; Thonart, P.; Haubruge, E.; Verheggen, F.J. Bacteria may enhance species association in an ant-aphid mutualistic relationship. Chemoecology 2015, 25, 223-232. [CrossRef]

32. Siddiqui, J.A.; Zou, X.; Liu, Q.; Zhang, H.; Lin, X.; Huang, X. Functional Morphology and Defensive Behavior in a Social Aphid. Insects 2019, 10, 163. [CrossRef]

33. Huang, X.L.; Xiang-Yu, J.G.; Ren, S.S.; Zhang, R.L.; Zhang, Y.P.; Qiao, G.X. Molecular phylogeny and divergence times of Hormaphidinae (Hemiptera: Aphididae) indicate Late Cretaceous tribal diversification. Zool. J. Linn. Soc. 2012, 165, 73-87. [CrossRef]

34. Aoki, S.; Kurosu, U. A Review of the Biology of Cerataphidini (Hemiptera, Aphididae, Hormaphidinae), Focusing Mainly on Their Life Cycles, Gall Formation, and Soldiers. Psyche A J. Ėntomol. 2010, 2010, 1-34. [CrossRef]

35. Shibao, H.; Morimoto, M.; Okumura, Y.; Shimada, M. Fitness costs and benefits of ant attendance and soldier production for the social aphid Pseudoregma bambucicola (Homoptera: Aphididae: Hormaphidinae). Sociobiology 2009, 54, 673-698.

36. Shibao, H. Reproductive schedule and factors affecting soldier production in the eusocial bamboo aphid Pseudoregma bambucicola (Homoptera, Aphididae). Insectes Sociaux 1999, 46, 378-386. [CrossRef]

37. Ledbetter, R.N.; Connon, S.A.; Neal, A.L.; Dohnalkova, A.; Magnuson, T.S. Biogenic Mineral Production by a Novel ArsenicMetabolizing Thermophilic Bacterium from the Alvord Basin, Oregon. Appl. Environ. Microbiol. 2007, 73, 5928-5936. [CrossRef] 
38. Srinivasan, S.; Hoffman, N.G.; Morgan, M.T.; Matsen, F.A.; Fiedler, T.L.; Hall, R.W.; Ross, F.J.; McCoy, C.O.; Bumgarner, R.; Marrazzo, J.M.; et al. Bacterial Communities in Women with Bacterial Vaginosis: High Resolution Phylogenetic Analyses Reveal Relationships of Microbiota to Clinical Criteria. PLoS ONE 2012, 7, e37818. [CrossRef]

39. Magoč, T.; Salzberg, S.L. FLASH: Fast Length Adjustment of Short Reads to Improve Genome Assemblies. Bioinformatics 2011, 27, 2957-2963. [CrossRef]

40. Bolger, A.M.; Lohse, M.; Usadel, B. Trimmomatic: A flexible trimmer for Illumina sequence data. Bioinformatics 2014, 30, 2114-2120. [CrossRef]

41. Edgar, R.C.; Haas, B.J.; Clemente, J.C.; Quince, C.; Knight, R. UCHIME Improves Sensitivity and Speed of Chimera Detection. Bioinformatics 2011, 27, 2194-2200. [CrossRef] [PubMed]

42. Edgar, R.C. UPARSE: Highly accurate OTU sequences from microbial amplicon reads. Nat. Methods 2013, 10, 996-998. [CrossRef] [PubMed]

43. Bokulich, N.A.; Subramanian, S.; Faith, J.J.; Gevers, D.; Gordon, J.I.; Knight, R.T.; Mills, D.A.; Caporaso, J.G. Quality-filtering vastly improves diversity estimates from Illumina amplicon sequencing. Nat. Methods 2013, 10, 57-59. [CrossRef] [PubMed]

44. Quast, C.; Pruesse, E.; Yilmaz, P.; Gerken, J.; Schweer, T.; Yarza, P.; Peplies, J.; Glöckner, F.O. The SILVA Ribosomal RNA Gene Database Project: Improved Data Processing and Web-Based Tools. Nucleic Acids Res. 2012, 41, D590-D596. [CrossRef] [PubMed]

45. Wang, Q.; Garrity, G.M.; Tiedje, J.M.; Cole, J.R. Naïve Bayesian Classifier for Rapid Assignment of rRNA Sequences into the New Bacterial Taxonomy. Appl. Environ. Microbiol. 2007, 73, 5261-5267. [CrossRef]

46. Katoh, K.; Standley, D.M. MAFFT Multiple Sequence Alignment Software Version 7: Improvements in Performance and Usability. Mol. Biol. Evol. 2013, 30, 772-780. [CrossRef]

47. Kumar, S.; Stecher, G.; Tamura, K. MEGA7: Molecular Evolutionary Genetics Analysis Version 7.0 for Bigger Datasets. Mol. Biol. Evol. 2016, 33, 1870-1874. [CrossRef]

48. Nguyen, L.T.; Schmidt, H.A.; Von Haeseler, A.; Minh, B.Q. IQ-TREE: A Fast and Effective Stochastic Algorithm for Estimating Maximum-Likelihood Phylogenies. Mol. Biol. Evol. 2015, 32, 268-274. [CrossRef]

49. Kimura, M. A simple method for estimating evolutionary rates of base substitutions through comparative studies of nucleotide sequences. J. Mol. Evol. 1980, 16, 111-120. [CrossRef]

50. Schloss, P.D.; Westcott, S.L.; Ryabin, T.; Hall, J.R.; Hartmann, M.; Hollister, E.B.; Lesniewski, R.A.; Oakley, B.B.; Parks, D.H.; Robinson, C.J.; et al. Introducing mothur: Open-Source, Platform-Independent, Community-Supported Software for Describing and Comparing Microbial Communities. Appl. Environ. Microbiol. 2009, 75, 7537-7541. [CrossRef]

51. Grice, E.A.; Kong, H.H.; Conlan, S.; Deming, C.B.; Davis, J.; Young, A.C.; Bouffard, G.G.; Blakesley, R.W.; Murray, P.R.; Green, E.D.; et al. Topographical and Temporal Diversity of the Human Skin Microbiome. Science 2009, 324, 1190-1192. [CrossRef] [PubMed]

52. Gherna, R.L.; Werren, J.H.; Weisburg, W.; Côté, R.; Woese, C.R.; Mandelco, L.; Brenner, D.J. Arsenophonus nasoniae gen. nov., sp. nov., the Causative Agent of the Son-Killer Trait in the Parasitic Wasp Nasonia vitripennis. Int. J. Syst. Bacteriol. 1991, 41, 563-565. [CrossRef]

53. Sebastien, A.; Gruber, M.A.M.; Lester, P.J. Prevalence and genetic diversity of three bacterial endosymbionts (Wolbachia, Arsenophonus, and Rhizobiales) associated with the invasive yellow crazy ant (Anoplolepis gracilipes). Insectes Sociaux 2012, 59, 33-40. [CrossRef]

54. Nováková, E.; Hypša, V.; A Moran, N. Arsenophonus, an emerging clade of intracellular symbionts with a broad host distribution. BMC Microbiol. 2009, 9, 143. [CrossRef]

55. Fukatsu, T.; Aoki, S.; Kurosu, U.; Ishikawa, H. Phylogeny of Cerataphidini aphids revealed by their symbiotic microorganisms and basic structure of their galls: Implications for host-symbiont coevolution and evolution of sterile soldier castes. Zool. Sci. 1994, 11, 613-623.

56. Tsuchida, T.; Koga, R.; Shibao, H.; Matsumoto, T.; Fukatsu, T. Diversity and geographic distribution of secondary endosymbiotic bacteria in natural populations of the pea aphid, Acyrthosiphon pisum. Mol. Ecol. 2002, 11, 2123-2135. [CrossRef]

57. Gauthier, J.-P.; Outreman, Y.; Mieuzet, L.; Simon, J.-C. Bacterial Communities Associated with Host-Adapted Populations of Pea Aphids Revealed by Deep Sequencing of 16S Ribosomal DNA. PLoS ONE 2015, 10, e0120664. [CrossRef]

58. Gómez-Valero, L.; Soriano-Navarro, M.; Pérez-Brocal, V.; Heddi, A.; Moya, A.; García-Verdugo, J.M.; Latorre, A. Coexistence of Wolbachia with Buchnera aphidicola and a Secondary Symbiont in the Aphid Cinara cedri. J. Bacteriol. 2004, 186, 6626-6633. [CrossRef]

59. Ma, B.; Hibbing, M.E.; Kim, H.S.; Reedy, R.M.; Yedidia, I.; Breuer, J.; Breuer, J.; Glasner, J.D.; Perna, N.T.; Kelman, A.; et al. Host Range and Molecular Phylogenies of the Soft Rot Enterobacterial Genera Pectobacterium and Dickeya. Phytopathology 2007, 97, 1150-1163. [CrossRef]

60. Czajkowski, R.; Pérombelon, M.C.M.; Van Veen, J.A.; Van Der Wolf, J.M. Control of blackleg and tuber soft rot of potato caused by Pectobacterium and Dickeya species: A review. Plant Pathol. 2011, 60, 999-1013. [CrossRef]

61. Charkowski, A.; Blanco, C.; Condemine, G.; Expert, D.; Franza, T.; Hayes, C.; Hugouvieux-Cotte-Pattat, N.; Solanilla, E.L.; Low, D.; Moleleki, L.; et al. The Role of Secretion Systems and Small Molecules in Soft-Rot Enterobacteriaceae Pathogenicity. Annu. Rev. Phytopathol. 2012, 50, 425-449. [CrossRef] [PubMed]

62. Züst, T.; Agrawal, A.A. Mechanisms and evolution of plant resistance to aphids. Nat. Plants 2016, 2, 15206. [CrossRef] [PubMed] 
63. Stouthamer, R.; Luck, R.F.; Hamilton, W.D. Antibiotics cause parthenogenetic Trichogramma (Hymenoptera/Trichogrammatidae) to revert to sex. Proc. Natl. Acad. Sci. USA 1990, 87, 2424-2427. [CrossRef]

64. Weeks, A.R.; Breeuwer, J.A.J. Wolbachia-induced parthenogenesis in a genus of phytophagous mites. Proc. R. Soc. Lond. Ser. B 2001, 268, 2245-2251. [CrossRef]

65. Arakaki, N.; Miyoshi, T.; Noda, H. Wolbachia-mediated parthenogenesis in the predatory thrips Franklinothrips vespiformis (Thysanoptera: Insecta). Proc. R. Soc. Lond. Ser. B 2001, 268, 1011-1016. [CrossRef]

66. Kittayapong, P.; Jamnongluk, W.; Thipaksorn, A.; Milne, J.R.; Sindhusake, C. Wolbachia infection complexity among insects in the tropical rice-field community. Mol. Ecol. 2003, 12, 1049-1060. [CrossRef] [PubMed]

67. Augustinos, A.A.; Santos-Garcia, D.; Dionyssopoulou, E.; Moreira, M.; Papapanagiotou, A.; Scarvelakis, M.; Doudoumis, V.; Ramos, S.; Aguiar, A.F.; Borges, P.A.V.; et al. Detection and Characterization of Wolbachia Infections in Natural Populations of Aphids: Is the Hidden Diversity Fully Unraveled? PLoS ONE 2011, 6, e28695. [CrossRef]

68. De Clerck, C.; Fujiwara, A.; Joncour, P.; Léonard, S.; Félix, M.-L.; Francis, F.; Jijakli, M.H.; Tsuchida, T.; Massart, S. A metagenomic approach from aphid's hemolymph sheds light on the potential roles of co-existing endosymbionts. Microbiome 2015, 3, 1-11. [CrossRef]

69. Herbert, J.J.; Horn, D.J. Effect of Ant Attendance by Monomorium minimum (Buckley) (Hymenoptera: Formicidae) on Predation and Parasitism of the Soybean Aphid Aphis glycines Matsumura (Hemiptera: Aphididae). Environ. Ėntomol. 2008, 37, 1258-1263. [CrossRef]

70. Nielsen, C.; Agrawal, A.A.; Hajek, A.E. Ants defend aphids against lethal disease. Biol. Lett. 2009, 6, 205-208. [CrossRef] 